\title{
Effect of physical therapy on joint range of motion and muscle collagen deposition in the golden retriever muscular dystrophy (GRMD) model
}

\author{
Efeito da fisioterapia na amplitude de movimento articular e deposição de \\ colágeno muscular no modelo golden retriever muscular dystrophy (GRMD)
}

Gaiad TP', Miglino MA', Zatz M², Hamlett WC³, Ambrosio CE'

\begin{abstract}
Objective: To elucidate the effect of physical therapy on joint range of motion (ROM) and muscle fibrosis in GRMD animals. Methods: This was a nonrandomized blinded study with a control group, with six months of intervention evaluated beforehand and afterwards. Six dystrophic male Golden Retrievers of mean age 10.16 \pm 3.46 months and weight $17.75 \pm 6.01 \mathrm{~kg}$ were divided into a treated group ( $n=3$ ) and an untreated group. These groups of dogs were named: G1=treated group before treatment; G2=treated group after treatment; G3=untreated group before treatment; and G4=untreated group after treatment. G1 underwent a physical therapy program that consisted of a 300-meter circuit with obstacles. Stifle, tarsal, elbow and carpal ROM were assessed using a goniometer before and after treatment. The area of collagen in the vastus lateralis muscle was measured using histomorphometry. The locations of collagen types I, III and IV were studied using immunohistochemistry. Results: The tarsal ROM values in G2 presented an increasing trend. The area of muscle collagen differed between the groups after treatment and an increasing trend in these values was observed in G4. Collagen types I and III were the ones most frequently observed, forming broad bands in the perimysium of both G2 and G4. Type I collagen was observed in the endomysium more than type III collagen. Type IV collagen was observed only in the basal layer. Conclusion: Physical Therapy seemed to improve tarsal ROM in the treated group without increasing muscular fibrosis.
\end{abstract}

Key words: muscular dystrophy; collagen; joints; physical therapy; animal model.

\section{Resumo}

Objetivo: Elucidar o efeito da fisioterapia na Amplitude de Movimento Articular (ADM) e na fibrose muscular em animais GRMD. Métodos: Estudo não randomizado, com grupo controle, cego, seis meses de intervenção, avaliação antes e depois da intervenção. Seis animais da raça Golden Retriever, distróficos, machos, média de idade 10,16 $\pm 3,46$ meses e peso de 17,75 $\pm 6,01 \mathrm{~kg}$ foram separados em grupo tratado $(n=3)$ e não tratado. Esses grupos de animais foram nomeados: $G 1=$ grupo tratado antes do tratamento; $G 2=$ grupo tratado após tratamento; G3=grupo não tratado antes do tratamento; G4=grupo não tratado após tratamento. O G1 participou do programa de fisioterapia que consistiu em um circuito de 300 metros com obstáculos. As ADMs do joelho, tarso, cotovelo e carpo foram avaliadas com goniômetro antes e após o tratamento. A área de colágeno do músculo vastus lateralis foi mensurada por histomorfometria, e a localização dos tipos de colágeno I, III e IV foi estudada por Imuno-histoquímica (IHC). Resultados: Os valores da ADM do tarso do G2 apresentaram uma tendência a aumentar. A área de colágeno muscular foi diferente entre os grupos após o tratamento, e uma tendência ao aumento desses valores no G4 foi observada. Os colágenos dos tipos I e III foram os mais observados, constituindo feixes largos no perimísio nos dois grupos (G2 e G4). O colágeno do tipo I foi mais observado no endomísio do que o colágeno do tipo III. O colágeno do tipo IV foi observado apenas na lâmina basal. Conclusão: A Fisioterapia parece aumentar a ADM do tarso dos animais do grupo tratado sem aumentar a fibrose muscular.

Palavras-chave: distrofia muscular; colágeno; articulações; fisioterapia; modelo animal.

Received: 14/08/2008 - Revised: 20/11/2008 - Accepted: 14/01/2009

${ }^{1}$ Department of Surgery, School of Veterinary Medicine and Animal Science, Universidade de São Paulo (USP-SP), São Paulo (SP), Brazil

${ }^{2}$ Human Genome Research Center, Biosciences Institute, USP-SP

${ }^{3}$ Department of Anatomy, Indiana University, School of Medicine - South Bend, South Bend, Indiana, USA

Correspondence to: Thais Peixoto Gaiad Machado, Rua Prof. Orlando Marques de Paiva, 87 - Departamento de Cirurgia/Setor de Anatomia, Cidade Universitária, CEP 05.508-270, São Paulo

(SP), Brazil, e-mail: thaispgm@usp.br 


\section{Introduction $: \therefore$.}

Lack of dystrophin protein in muscle cells is characteristic of duchenne muscular dystrophy (DMD), which is a progressive and fatal X-linked genetic disorder. Animal models have been studied to identify efficient treatments for this disease in humans ${ }^{1}$.

The golden retriever muscular dystrophy (GRMD) model has been widely studied ${ }^{2}$, since it presents muscle abnormalities that are closest to the ones seen in humans: increased creatine kinase (CK) activity, muscle hypotrophy associated with contractures, muscle necrosis, degeneration, endomysial and perimysial fibrosis and cardiomyopathy ${ }^{3}$.

So far, no treatment to stop DMD progression has been found. Physical therapy has been used to reduce the muscular, skeletal, cardiac and vascular abnormalities that develop in association with muscle strength loss. The main objective in such therapy is to prevent muscle contractures and bone deformities ${ }^{4}$.

Studies on physical therapy interventions on the GRMD model are scarce. Among humans, physiotherapeutic methods have yielded controversial results 5 . Some of these methods have suggested that DMD patients should perform moderate exercises ${ }^{6}$, while others have suggested that these patients should undertake recreational activities and activities of daily living ${ }^{7,8}$. However, few studies have actually assessed benefits ${ }^{9,10}$.

According to Grange and Call ${ }^{11}$, the same exercise used to increase muscle strength and endurance in normal individuals can exacerbate muscle damage in a dystrophic muscle. The authors suggested that a threshold must be defined to guide suitable exercise prescription for DMD patients. Kimura et al. ${ }^{12}$, however, showed that immobility could reduce muscle fiber necrosis in muscular dystrophy cases.

Different types of exercise prescriptions have been well defined in the dystrophic mouse mode ${ }^{5,11,13}$. In contrast, this model presents significant differences regarding the amount of muscle mass and the characteristics of its clinical progression that make it difficult to directly apply these results to humans ${ }^{1}$.

Assessment of passive joint mobility is an indicator of muscle flexibility and contracture. Its use in some studies on dogs has been described ${ }^{14,15}$ to aid in making decisions on appropriate therapeutic interventions and to document the effectiveness of these interventions.

According to Valentine et al. ${ }^{16}$, progressive endomysial and perimysial fibrosis is a common characteristic in DMD patients and in the GRMD model, but it is not observed in the dystrophic mouse model. They suggested that increased interstitial collagen levels could interfere with normal muscle metabolism, thereby leading to abnormal regeneration, decreased vascular perfusion and mechanical restrictions.

Dystrophic muscle tissue presents abnormally increased muscle collagen fibers due to repeated degeneration and regeneration of dystrophin-deficient muscle tissue. Some studies have reported that collagen fiber types I, III and IV are present, in increased proportions, in muscular dystrophy cases ${ }^{17-19}$.

Considering that GRMD presents progressive mobility restriction and muscle fibrosis due to repeated muscle lesions, the aim of the present study was to elucidate the effect of motor physical therapy on passive joint mobility and muscle morphology among GRMD dogs.

\section{Methods ::}

\section{Animals}

Six dystrophic male Golden Retrievers were selected from the GRMD-Brazil kennel of the Anatomy Sector, Department of Surgery, Universidade de São Paulo (USP). The Human Genome Center, Institute of Biology, USP, had previously used DNA analysis on blood samples from these dogs, taken between the first and third day of life, to confirm the presence of muscular dystrophy. This research was approved by the Bioethics Commission of the School of Veterinary Medicine and Animal Science, USP, under protocol number 900/2006.

\section{Study design}

The GRMD animals were separated into two groups: treated and untreated, according to biometric data. One group of three dogs received physical therapy (treated group) and the remaining three dogs (untreated group) did not receive any treatment. The groups were analyzed before and after the time of treatment, thus, for analysis, they were subdivided into: G1 = treated group before treatment; G2 = treated group after treatment; G3 = untreated group before treatment; G4 = untreated group after treatment.

No statistical difference between G1 and G3 was observed with regard to the mean weights and ages (Table 1). After the first range of motion (ROM) evaluation and muscle biopsy collection, G1 underwent the physical therapy protocol.

G3 continued to follow the same routine of kennel life. An open-air enclosure of $20 \mathrm{~m}^{2}$ in area was available during the day, while at night, the dogs were kept in closed pens of 1 to $3 \mathrm{~m}^{2}$ in area. Daily activities consisted of feeding, cleaning care and clinical analysis. 


\section{Intervention}

The type, frequency and duration of the exercise protocol were selected based on the published recommendations for DMD patients ${ }^{6-8,20,21}$ and on field research by the Brazilian Association for Muscular Dystrophy (ABDIM). The motor physical therapy sessions were administered three times a week for 45 minutes to each animal, for six months. The physical therapy program consisted of a free walking activity with the objectives of maintaining the ROM and functional activities of the affected dogs, as well as preventing cardiac, pulmonary and skeletal complications.

An oval area with diameters of $30 \times 5$ meters and a total length track of 60 meters was constructed for physical

Table 1. Biometric features of the GRMD dogs in groups G1 and G3.

\begin{tabular}{llcc}
\hline Groups & Animal identification & Age (months) & Weight $(\mathrm{kg})$ \\
\hline G1 & Bl1M4 & 9 & 18.5 \\
\cline { 2 - 4 } & BR3M5 & 13 & 21.2 \\
\cline { 2 - 4 } & CH1M3 & 6 & 18 \\
\cline { 2 - 4 } & G1 (mean value $\pm S D)$ & $9.66 \pm 3.51$ & $19.23 \pm 1.72$ \\
\hline G3 & BR3M7 & 13 & 13.5 \\
\cline { 2 - 4 } & BR3M2 & 13 & 22 \\
\cline { 2 - 4 } & CH1M5 & 6 & 20 \\
\cline { 2 - 4 } & G3 (mean value $\pm S D)$ & $10.67 \pm 4.04$ & $18.5 \pm 4.44$ \\
\hline \multirow{2}{*}{} & $p$ value & 0.354 & 0.401 \\
\hline
\end{tabular}

G1: treated group before treatment; G3: untreated group before treatment; $t$ test comparing groups, $p<0.05$.

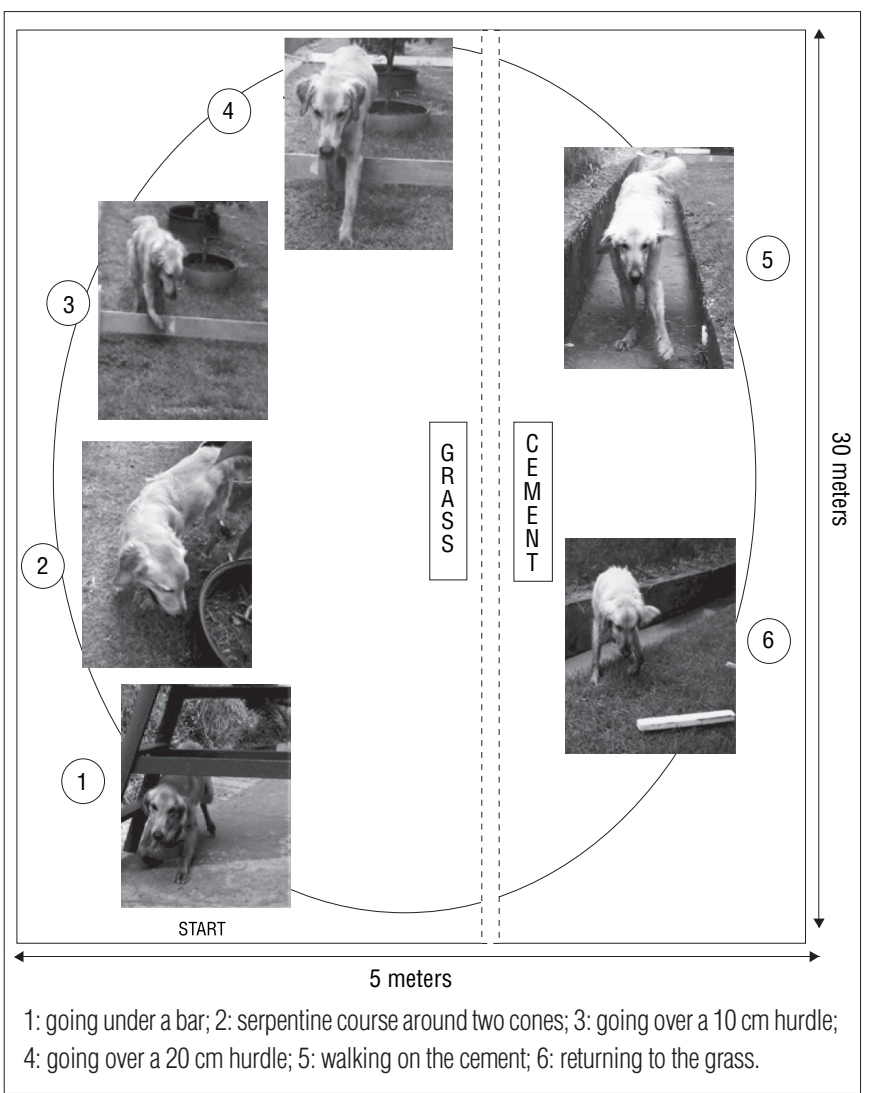

Figure 1. Physical therapy protocol and obstacles. therapy sessions (Figure 1). One half was composed of grass and contained four obstacles. The obstacles consisted of, in order: a bar that the dogs were required to go under; a serpentine course around two cones; a $10 \mathrm{~cm}$ hurdle that they were required to go over; and a similar $20 \mathrm{~cm}$ hurdle. All the obstacles required head, trunk and limb flexion. The other half of the course was concrete and contained no obstacles. The dogs were required to complete five circuits of the course, making a total of $300 \mathrm{~m}$. At the end of the 300 meters, they rested comfortably on their sides. If they were seen to present halting gait and increased respiration, they were allowed to rest briefly before completing the circuit.

\section{Outcome measurements}

Outcomes were measured in terms of the ROM of the elbow, carpal, stifle and tarsal joints and the area of collagen on the vastus lateralis muscle in relation to the total area of muscle tissue, before and after the intervention program. After treatment, muscle collagen types I, III and IV were assessed using immunohistochemical techniques to make inferences about the adaptations of the dystrophic muscle due to fibrosis.

\section{Joint range of motion (ROM)}

Flexion and extension joint ROM data were collected using a manual universal goniometer with $2^{\circ}$ gradations. During data collection, the dogs did not receive any sedation, in order to allow normal expression of pain due to over-extension or overflexion of joints.

They were comfortably positioned in lateral recumbence. Considering that no standard measurements of the anatomical joint positions for the Golden Retriever breed exist, we established a joint ROM assessment through the complete extent of flexion and extension, as described by Jaegger, Marcellin-Little and Levine ${ }^{22}$ in Labrador Retrievers.

Measurements were made while keeping the dog's joints moving slowly and continuously to avoid muscle stretch resistance. Maximum flexion and extension were determined by the endurance that the animals presented at the end of the ROM and any pain signals such as contralateral limb movements of discomfort.

The center of the goniometer was positioned on each joint axis during the measurements. The proximal and distal arms of the goniometer were positioned on selected anatomical landmarks of the limbs, in accordance with Jaegger, Marcellin-Little and Levine ${ }^{22}$. Three consecutive measurements were made, and the mean value and standard deviation were calculated. 


\section{Muscle biopsy}

Muscle fragments were collected from the vastus lateralis muscle of each dog, before and after treatment. To avoid any loss of motor function in these GRMD animals, a single muscle was chosen to represent the pelvic limb. The hind limbs are considered more affected in the canine dystrophy model ${ }^{3}$, and the vastus lateralis was described by Childers et al..$^{23}$ as a muscle group that incurs damage and regeneration between the ages of one and six months in GRMD dogs.

An open biopsy was performed and a $1 \mathrm{~cm}^{2}$ fragment was collected from the middle portion of the muscle. After venous cannulation and fluid therapy, the dogs were subjected to an anesthetic protocol: acepromazine maleate (Acepran, Laboratório Univet S/A., Brazil) and tramadol hydrochloride (Tramal, Laboratório Pfizer Ltda, Brazil) (0.05 mg/km and $2 \mathrm{mg} / \mathrm{kg}$, respectively), intramuscularly. The skin incision, subcutaneous tissue and muscle fascia received local infiltrative anesthesia consisting of lidocaine hydrochloride $2 \%$ (Lidol $2 \%$, Hipolabor Farmacêutica Ltda., Brazil) without vasoconstrictor $(7 \mathrm{mg} / \mathrm{kg}$ ). Propofol (propofol, Laboratório Eurofarma, Brazil) $(2.5 \mathrm{mg} / \mathrm{kg}$ ) was administered intravenously prior to muscle biopsy. Intravenous ketoprofen (ketoprofen, Laboratório Merial, Brazil) (1 mg/kg) was used postoperatively. Analgesia using the same drugs was administered orally for 3 to 5 days afterwards. Cephalexin $\left(\mathrm{Keflex}^{\circledR}\right.$, Antibióticos do Brasil Ltda., Brazil) was used for antibiotic therapy (20 mg/kg BID), for seven days. The biopsies before and after treatment were performed around the scar tissue in order to avoid scar fibrosis in the muscle fragments.

\section{Muscle collagen quantification}

Muscle fragments were cooled using liquid nitrogen and were frozen at $-80^{\circ} \mathrm{C}$. Cross-sections of 6 to $8 \mu \mathrm{m}$ in thickness were made using a Leica Cryostat CM 1850 at $-20^{\circ} \mathrm{C}$. The crosssections were stained using picrosirius red in order to distinguish collagen from skeletal muscle. Picrosirius is a solution of sirius red and picric acid that stains collagen fibers red and muscle tissue yellow.

To accurately quantify collagen-positive areas, slides from thirty randomly selected low-power fields per muscle section from each dog were viewed under a microscope (Axioplan 2; Carl Zeiss, Inc.). Digital images were captured on a video archival system using a digital TV camera system (AxioCam high-resolution color, Carl Zeiss, Inc.). An automated software analysis program (KS400, Carl Zeiss, Inc.) was used to determine the percentage of stained areas on the digital photomicrographs, in accordance with Sato et al. ${ }^{24}$.
The area of collagen was measured in $\mu \mathrm{m}^{2}$. The mean values and standard deviations from the thirty fields from each animal were converted into percentages of the total muscle area.

\section{Immunohistochemistry}

Sections were stained for collagen types I, III and IV. Primary mouse anti-collagen types I and III (Calbiochem $\left.{ }^{\circledR}\right)$ and goat anti-collagen type IV (Bioreagents ${ }^{\circledR}$ ) were applied, separately. The primary antibody dilutions were: collagen type I, 1:500; collagen type III, 1:750; and collagen type IV, 1:250). After being washed three times in phosphate-buffered saline (PBS), the sections were incubated for 45 minutes with secondary biotinylated antibody (Dako Ltd. ${ }^{\circledR}$ ) in a damp chamber at room temperature. After three more rinses in PBS, streptavidin was applied for 45 minutes. The sections were washed with PBS and covered with DAB for 1 to 2 minutes. They were then mounted using Paramount, and photomicrographs were made using an optical microscope (Axioscope, Zeiss ${ }^{\circledR}$ ) and an Olympus BX 60 camera. All the incubations were performed in a damp chamber at room temperature. On control sections, the primary antibody was omitted.

\section{Statistical analysis}

The mean values for joint ROM and area of collagen in the muscles of the GRMD dogs, between the treated and untreated groups, were compared using the $t$ test. Before and after-treatment values were compared using the paired $t$ test. The values were analyzed and considered statistically different when the p-value was $<0.05$.

\section{Results : :}

ROM measurements were made in all groups. No significant difference was observed in tarsal ROM measurement between G1 and G3 ( $\mathrm{p}=0.419)$. After treatment, there was statistical difference in tarsal ROM measurement between the groups (comparison between G2 and G4, p=0.040), and G2 presented a trend towards tarsal ROM increase (Table 2). The mean elbow ROM values between G1 and G3 were not statistically different before the treatment $(\mathrm{p}=0.227)$ and maintained this characteristic during the study period ( $\mathrm{p}=0.500$ ). The carpal ROM of both GRMD groups was hyperflexed before and after treatment. The mean ROM values of the two GRMD groups before (G1 and G3) and after six months of intervention (G2 and G4) were not statistically different for all the joints evaluated.

The mean area of the collagen bundles in healthy muscle was $1.69 \%$ of the total muscle area $\left(603.126 \mu \mathrm{m}^{2}\right)$ and was lower 
than the mean value for the six GRMD dogs (6.95\% \pm 0.32$)$ before treatment. There was no difference between G1 $(5.53 \% \pm 1.77)$ and G3 (5.80\% \pm 3.57$)(\mathrm{p}=0.929)$. After treatment, there was a difference between G2 and G4 ( $p=0.014)$ (Figure 2).

There was no statistical difference when comparing before and after treatment values within the groups. A trend towards increased collagen area in G4 was observed, without statistical difference $(\mathrm{p}=0.288)$ (Table 3$)$.
In immunohistochemical analysis, the perimysium of all animals stained positively for collagen types I and III in enlarged tracts. The endomysium stained positively for collagen type I especially (Figures 3A and B) and for collagen III in thick tracts (Figures 3C and D). No significant difference between G2 and G4 was observed. The basal layer of muscle fibers consisting of thick tracts stained for collagen type IV, thus not differing from healthy muscle (Figures $3 \mathrm{E}$ and F).

Table 2. Mean joint range of motion (ROM) data from GRMD dogs before and after treatment (in degrees).

\begin{tabular}{lrccccc} 
& G1 & G3 & $p$ value & G2 & G4 & $p$ value \\
\hline Elbow & $123.33 \pm 5.77$ & $116.67 \pm 12.5$ & 0.227 & $120 \pm 5$ & $120 \pm 5$ & 0.500 \\
\hline Carpal joint & $145 \pm 13.2$ & $157.33 \pm 4.04$ & $0.017^{\star}$ & $145 \pm 5$ & $150 \pm 5$ & 0.112 \\
\hline Stifle & $105.67 \pm 6.02$ & 110 & $0.008^{\star}$ & $116.67 \pm 7.63$ & $118.33 \pm 10.4$ & 0.371 \\
\hline Tarsal joint & $115 \pm 18.0$ & $116.67 \pm 12.5$ & 0.419 & $141.67 \pm 7.63$ & $128.33 \pm 12.5$ & $0.040^{\star}$ \\
\hline
\end{tabular}

G1: treated group before treatment; G2: treated group after treatment; G3: untreated group before treatment; G4: untreated group after treatment. * $t$ test, $p$ value $<0.05$.

Table 3. Area of collagen deposition in GRMD dogs expressed as percentage of the total area $(603.126 \mu \mathrm{m} 2)$.

\begin{tabular}{lccc}
\hline & Treated $(\mathrm{n}=3)$ & Untreated $(\mathrm{n}=3)$ & $p$ value \\
\hline Before treatment & $5.53 \% \pm 1.76(\mathrm{G} 1)$ & $5.80 \% \pm 3.57(\mathrm{G} 3)$ & $0.929^{\star}$ \\
\hline After treatment & $5.58 \pm 1.11(\mathrm{G} 2)$ & $9.64 \pm 1.53(\mathrm{G} 4)$ & $0.014^{\star} \dagger$ \\
\hline$p$ value & $0.879^{\star \star}$ & $0.239^{\star \star}$ & \\
\hline
\end{tabular}

${ }^{*} t$ test $/{ }^{* *}$ paired $t$ test. $\uparrow p<0.05$. Note: values are expressed as mean $\pm S D$.
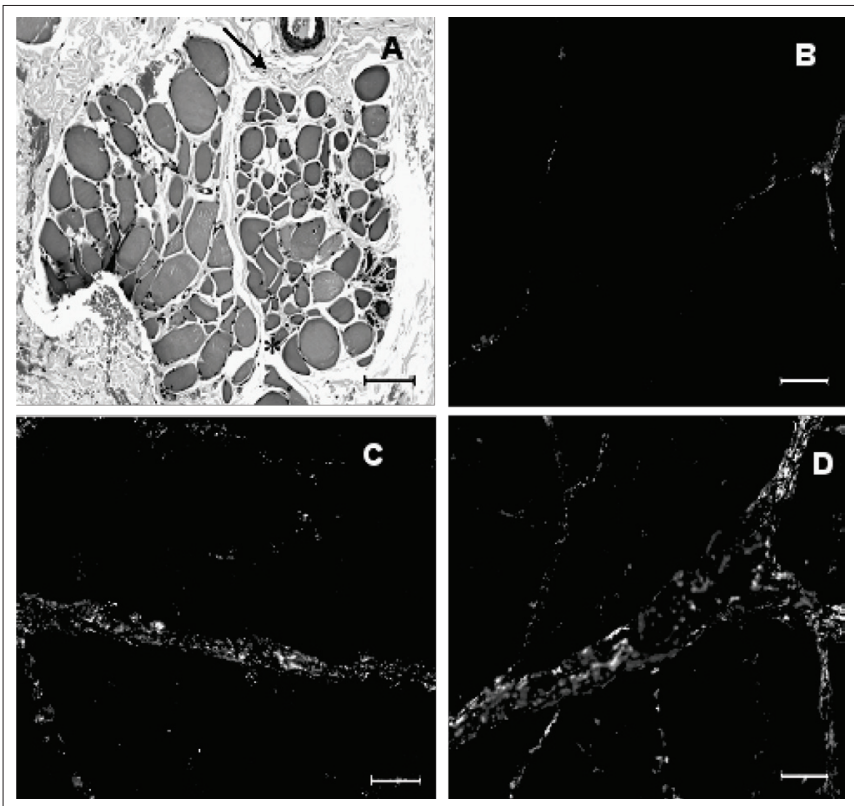

Figure 2. A. Photomicrograph of the vastus lateralis muscle of an 18month-old dystrophic dog. Perimysial $(\rightarrow)$ and endomysial $(*)$ connective tissue, stained with HE. B. Photomicrograph under polarized light of normal adult skeletal muscle, stained with picrosirius red. C. Photomicrograph under polarized light of dystrophic vastus lateralis muscle in 18-month-old untreated dog (G4), stained with picrosirius red. D. Photomicrograph under polarized light of dystrophic vastus lateralis muscle in 18-month-old treated animal (G2), stained with picrosirius red.

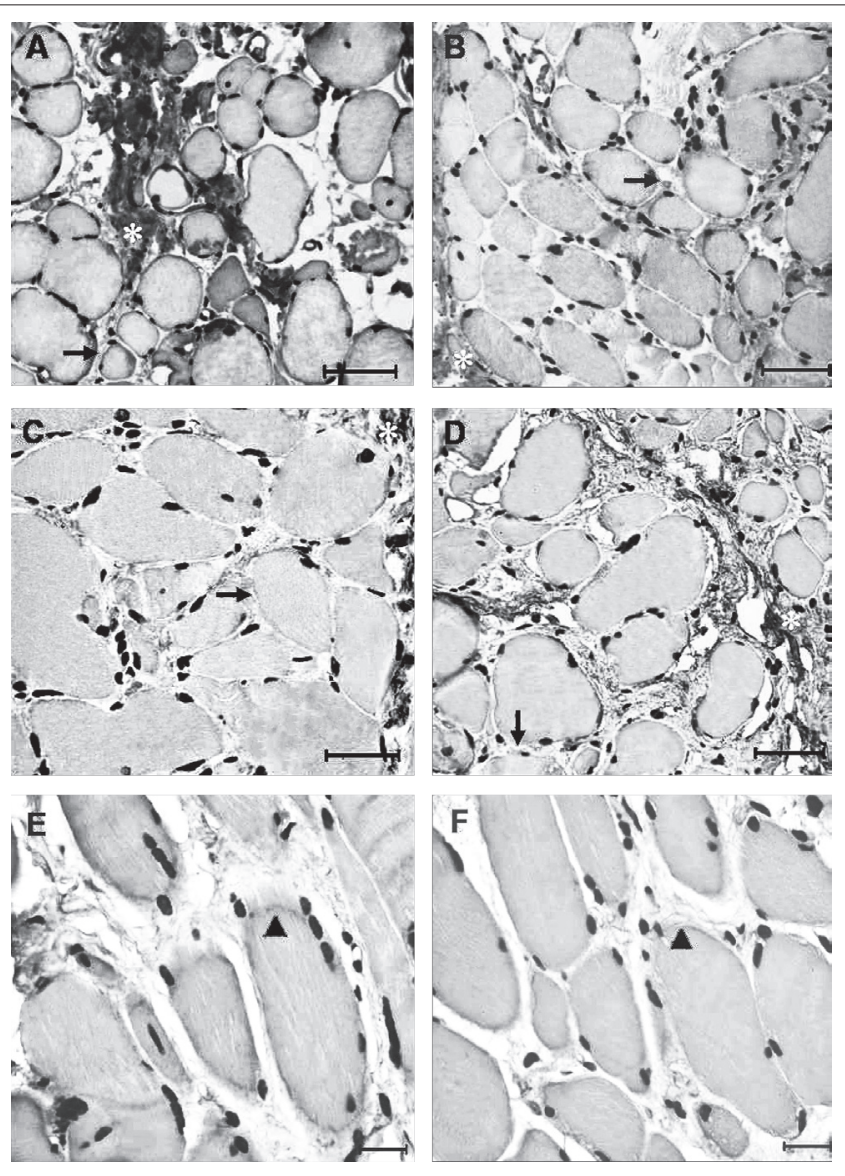

Figure 3. Photomicrograph of immunohistochemical analysis of collagen in skeletal muscle of dystrophic dogs. Positive immunostaining for collagen type I, in dogs from G4 (A) and G2 (B); bar=40 $\mu \mathrm{m}$. Positive immunostaining for collagen type III, in dogs from G4 (C) and G2 (D), bar=40 $\mu \mathrm{m}$. Positive immunostaining for collagen type IV, in dogs from $G 4(E)$ and $G 2(F)$; bar $=20 \mu \mathrm{m}$. In $A, B, C$ and $D$ : perimysial fibrosis $(*)$ and endomysial fibrosis $(\rightarrow)$; in $\mathrm{E}$ and $\mathrm{F}$ : basal layer of muscle fiber $(\boldsymbol{\nabla})$. 


\section{Discussion $\because:$.}

The dogs that underwent physical therapy showed increased tarsal ROM and maintenance of the area of muscle collagen. This was not observed in the untreated group.

Compared with healthy Golden Retrievers, the mean tarsal ROM values were found to be limited in dystrophic dogs ${ }^{25}$. In that study, normal dogs showed mean values of $123.57^{\circ} \pm 8.69$ for the tarsal joint at a mean age of 17 months.

In another GRMD group, Kornegay et al. ${ }^{26}$ described tarsal ROM in 13 dogs aged three to six months. They observed a significant reduction in ROM over this period, with a median value of $117^{\circ} \pm 24.5$ at six months of age. There was a decrease in tarsal ROM associated with aging beyond six months of age.

In our group, the main ROM reductions were in the stifle and tarsal joints associated with carpal hyperflexion during gait in most of the dogs around the age of four months ${ }^{27}$. This situation leads to a characteristic gait, namely plantigrady for tarsal ROM and palmigrady for carpal ROM.

These ROM abnormalities, associated with significant loss of muscle mass, change postural conformation and progressively restrict gait. Maintenance of, or increase in, the ROM of this joint is not common and may be attributed to physical therapy, since it was only observed in the treated group.

The GRMD dogs in the treated and untreated groups presented ROM values that suggested carpal joint over-flexion. Kornegay et al. ${ }^{26}$ also found increased values for the carpal ROM in GRMD animals.

Dystrophic animals develop defects in the thoracic limbs later than in the pelvic limbs ${ }^{3}$. Moreover, during quadruped posture and gait, the forelimbs carry more body weight than the pelvic limbs. Over-flexion of the carpal joint may result from overload due to primary changes in the hind limbs, such as tarsal and stifle ROM reduction.

The proximal joints, such as the elbow and stifle, seem to suffer fewer modifications than the distal joints, such as the carpal and tarsal joints. Further follow-up studies on these two proximal joints may elucidate their progression in the canine muscular dystrophy model.

In association with the ROM abnormalities, these dogs showed significant histopathological characteristics of dystrophic muscle, particularly endomysial and perimysial fibrosis. The histological features of dystrophic muscles have been described, including fiber diameter changes, necrosis, regeneration, hyalinization and inflammatory response ${ }^{16,17,28,29}$. The common features of progressive endomysial and perimysial fibrosis between the GRMD model and humans ${ }^{16}$ make it possible to answer some questions using animal models of DMD for further application on human beings.
The relationship between fibrosis and therapeutic exercise in the GRMD model has not been studied yet. It has been found that the muscle fibers of dystrophic dogs that reach the degenerative stage are gradually replaced by fibrous and adipose connective tissue ${ }^{16}$.

Before treatment, the dystrophic dogs already presented increased areas of collagen on muscle tissue, compared with healthy muscle. The difference observed between G2 and G4 indicated a trend towards connective tissue increase in G4. Since G4 did not undergo physical therapy, it is possible that the protocol used gave rise to positive adaptations to the muscle morphology of the treated group.

Immobility and dystrophic muscle have been discussed by some authors with different conclusions. Kimura et al. ${ }^{12}$ reported the case of a three-year-old boy with a diagnosis of spina bifida and DMD. A muscle biopsy on this patient showed that necrosis and regeneration of muscle fiber was more prevalent in the biceps brachii (with normal movement) than in the gastrocnemius muscle (without movement). This suggests that immobility reduces muscle fiber necrosis in dystrophin-deficient muscular dystrophy.

In contrast, Mackey, Donnelly and Roper ${ }^{30}$ compared healthy endurance-trained and inactive individuals and found a negative association between aerobic capacity and the collagen-type III and IV content of the endomysium. These results suggest that muscle inactivity leads to great deposition of these types of collagen.

Collagen fibers are the main component of connective tissue. However, each type of collagen protein is associated with certain characteristics of the tissue. Collagen types I and III are interstitial proteins found in different proportions in muscle tissue according to its function, adaptations or pathological conditions. Collagen type I restricts the tissue, while type III is observed in tissues that are more flexible. Collagen type IV can be found in the basal layer and has a structural function ${ }^{30}$. For this reason, studying the different types of collagen may clarify the adaptive mechanisms of dystrophic muscles.

Through immunohistochemical analysis on the locations of collagen types, there were greater amounts of collagen types I and III in the perimysium. The endomysium stained mainly for collagen type I, which suggests less flexibility and restricted movement. No visual differences between G2 and G4 were observed. A quantitative study is needed for better comprehension of the proportions and locations of collagen types in dystrophic muscle tissue.

Physical therapy is likely to improve tarsal ROM in the treated group without increasing muscle fibrosis. Because muscular dystrophy is a progressive disease with cycles of muscle degeneration and regeneration, the maintained values in areas of collagen in the dogs that underwent physical therapy suggests that movement may play an important role in fibrosis adaptation. 
Adaptations to exercise in dystrophic muscle are well known from other models such as mice, hamsters and rabbits? The main goal of those studies was to elucidate the effect of exercise on functional performance and muscle pathology. Grange and Call ${ }^{13}$ suggested that a directed exercise study on GRMD dogs would be a good bridge to human studies.

Does motor physical therapy play a positive role in muscle flexibility and contractures among muscular dystrophy patients? How does dystrophic muscle tissue respond to such recruitment? Fibrosis seems to provide an insight towards understanding this process, because it is the result of repeated cycles of muscle degeneration and regeneration in the absence of dystrophin. Phenotypic differences, age and routines of daily life are important factors that must be considered in muscle fibrosis studies because of variability in the progress of the disease.

\section{Conclusion $: \because$.}

The relationship between movement and muscle fibrosis deposition is not well known in DMD. Because of the similarities in the progression of GRMD and human DMD disease, studies using the dog model can provide new insights for physical therapy protocols. Therapeutic exercise for muscular dystrophy cases must be well-defined and aim towards positively influencing musculoskeletal function with minimal muscle fiber deterioration.

\section{Acknowledgements : :}

This research was supported by CAPES (Coordenação de Aperfeiçoamento de Pessoal de Nivel Superior) and FAPESP (Fundação de Amparo à Pesquisa do Estado de São Paulo), CEPID Process no. 1998/14254-2. We would like to thank Dr. Fátima Aparecida Caromano from the Department of Physical Therapy, School of Medicine of Universidade de São Paulo for her helpful suggestions. We would also like to thank Prof. Joe N. Kornegay and Dr. Janet Bogan from the Department of Veterinary Medicine and Surgery, College of Veterinary Medicine of the University of Missouri, Columbia, USA, who were responsible for donating the first GRMD carrier female and establishing the Brazilian colony of GRMD dogs.

\section{References}

1. Vainzof M, Ayub-Guerrieri D, Onofre PC, Martins PC, Lopes VF, Zilberztajn $D$, et al. Animal models for genetic neuromuscular diseases. J Mol Neurosci. 2008;34(3):241-8.

2. Collins CA, Morgan JE. Duchenne's muscular dystrophy: animal models used to investigate pathogenesis and develop therapeutic strategies. Int J Exp Pathol. 2003;84(4):165-72.

3. Howell JM, Fletcher S, Kakulas BA, O'Hara M, Lochmuller H, Karpati G. Use of the dog model for Duchenne muscular dystrophy in gene therapy trials. Neuromuscul Disord. 1997;7(5):325-8.

4. Strober JB. Therapeutics in duchenne muscular dystrophy. NeuroRx. 2006;3(2):225-34.

5. Carter GT, Abresch RT, Fowler WM Jr. Adaptations to exercise training and contraction-induced muscle injury in animal models of muscular dystrophy. Am J Phys Med Rehabil. 2002;81 Suppl 11:S151-61.

6. McDonald CM. Physical activity, health impairments, and disability in neuromuscular disease. Am J Phys Med Rehabil. 2002;81 Suppl $11: 108-20$

7. de Araújo Leitão AV, Duro LA, de Andrade Penque GMC. Progressive muscular dystrophy-Duchenne type. Controversies of the kinesitherapy treatment. Sao Paulo Med J. 1995;113(5):995-9.
8. Caromano FA. Características do portador de Distrofia Muscular de Duchenne (DMD): revisão. Arq Ciências Saúde UNIPAR. 1999;3(3):211-8.

9. Uchikawa K, Liu M, Hanayama K, Tsuji T, Fujiwara T, Chino N. Functional status and muscle strength in people with Duchenne muscular dystrophy living in the community. J Rehabil Med. 2004;36(3):124-9.

10. Vignos PJ, Wagner MB, Karlinchak B, Kairji B. Evaluation of a program for long-term treatment of Duchenne muscular dystrophy. Experience at the University Hospitals of Cleveland. J Bone Joint Surg Am. 1996;78(12):1844-52.

11. Grange RW, Call JA. Recommendations to define exercise prescription for Duchenne Muscular Dystrophy. Exerc Sport Sci Rev. 2007;35(1):12-7.

12. Kimura S, Ikesawa M, Nomura K, Ito K, Ozasa S, Ueno H, et al. Immobility reduces muscle fiber necrosis in dystrophin deficient muscular dystrophy. Brain Dev. 2006;28(7):473-6.

13. Kumar A, Boriek AM. Mechanical stress activates the nuclear factor-kappaB pathway in skeletal muscle fibers: a possible role in Duchenne muscular dystrophy. FASEB J. 2005;17(3):386-96

14. Corfield GS, Read RA, Eastley KA, Richardson JL, Robertson ID, Day R Assessment of the hip reduction angle for predicting osteoarthritis of the hip in the Labrador retriever. Aust Vet J. 2007;85(16):212-6. 
15. Nicholson HL, Osmotherly PG, Smith BA, McGowan CM. Determinants of passive hip range of motion in adult Greyhounds. Aust Vet J. 2007;85(6):217-21.

16. Valentine BA, Cooper BJ, Cummings JF, de Lahunta A. Canine X-linked muscular dystrophy: morphologic lesions. J Neurol Sci. 1990;97(1): $1-23$.

17. Passerini L, Bernasconi P, Baggi F, Confalonieri P, Cozzi F, Cornelio F, et al. Fibrogenic cytokines and extent of fibrosis in muscle of dogs with $\mathrm{X}$-linked golden retriever muscular dystrophy. Neuromuscul Disord. 2002;12(9):828-35.

18. Hantai D, Labat-Robert J, Grimaud JA, Fardeau M. Fibronectin, laminin, type I, III and IV collagens in Duchenne's muscular dystrophy, congenital muscular dystrophies and congenital myopathies: an immunocytochemical study. Connect Tissue Res. 1985;13(4):273-81.

19. Duance VC, Stephens HR, Dunn M, Bailey AJ, Dubowitz V. A role for collagen in the patogenesis of muscular dystrophy? Nature. 1980;284(5755):470-2.

20. Eagle M. Report on the muscular dystrophy campaign workshop: Exercise in neuromuscular diseases Newcastle, January 2002. Neuromuscul Disord. 2002;12(10):975-83.

21. Ansved T. Muscular dystrophies: influence of physical conditioning on the disease evolution. Curr Opin Clin Nutr Metab Care. 2003;6(4): 435-9.

22. Jaegger G, Marcellin-Little DJ, Levine D. Reliability of goniometry in Labrador Retrievers. Am J Vet Res. 2002;63(7):979-86.
23. Childers MK, Okamura CS, Bogan DJ, Bogan JR, Petroski GF, McDonald K, et al. Eccentric contraction injury in dystrophic canine muscle. Arch Phys Med Rehabil. 2002;83(11):1572-8.

24. Sato Y, Murase K, Kato J, Kobune M, Sato T, Kawano Y, et al. Resolution of liver cirrhosis uring vitamina A-coupled liposomes to deliver siRNA against a collagen-specific chaperone. Nat Biotechnol. 2008;26(4):413-42.

25. Gaiad TP, Mendes M, Miglino MA, Abatemarco A, Ambrosio CE. Amplitude de movimento articular de animais golden retriever normais e do modelo golden retriever muscular dystrophy. Int J Morphol. 2006; 25.

26. Kornegay JN, Sharp NJ, Schueler R0, Betts CW. Tarsal joint contracture in dogs with golden retriever muscular systrophy. Lab Anim Sci. 1994;44(4):331-3.

27. Kerkis I, Ambrosio CE, Kerkis A, Martins DS, Zucconi E, Fonseca SAS, et al. Early transplantation of human immature dental pulp stem cells from baby teeth to golden retriever muscular dystrophy (GRMD) dogs: Iocal or systemic? J Transl Med. 2008;6:35.

28. Nguyen F, Cherel Y, Guigand L, Goubault-Leroux I, Wyers M. Muscle lesions associated with dystrophin deficiency in neonatal golden retriever puppies. J Comp Pathol. 2002;126(2-3): 100-8.

29. Cozzi F, Cerletti M, Luvoni GC, Lombardo R, Brambilla PG, Faverzani S, et al. Development of muscle pathology in canine X-linked muscular dystrophy.ll. Quantitative characterization of histopathological progression during postnatal skeletal muscle development. Acta Neuropathol. 2001;101(5):469-78.

30. Mackey AL, Donnelly AE, Roper HP. Muscle connective tissue content of endurance-trained and inactive individuals. Scand J Med Sci Sports. 2005;15(6):402-8. 